\title{
Successful guidewire placement across hilar malignant biliary stricture after deceased donor liver transplantation using new digital cholangioscopy
}

A 70-year-old man with metastatic rectal cancer was referred to our department for endoscopic management of obstructive jaundice due to metastatic lymph nodes. He previously received deceased donor liver transplantation with duct-toduct biliary reconstruction. Computed tomography and magnetic resonance cholangiopancreatography showed hilar biliary stricture due to metastatic lymph nodes at the duct-to-duct anastomosis ( Fig. 1, $>$ Fig. 2). Endoscopic retrograde cholangiopancreatography revealed a markedly dilated recipient bile duct and a stricture of the donor hepatic duct ( Fig.3). Multiple attempts to pass the hilar stricture using a 0.035-inch hydrophilic guidewire and a cannula or a rotatable sphincterotome failed because a guidewire easily advanced to the remnant cystic duct just below the stricture. Hence, after endoscopic sphincterotomy, guidewire passage using SpyGlass DS Direct Visualization System (SpyDS; Boston Scientific Japan, Tokyo, Japan) was attempted. Cholangioscopy allowed direct visualization of both torturous biliary stricture with non-tumorous mucosa and the wide-opening remnant cystic duct ( Fig.4). A guidewire was readily passed through the stricture into the left intrahepatic duct under SpyDS and fluoroscopy guidance ( $\triangleright$ Fig.5). Given the presence of high-grade hilar biliary stricture, bilateral metal stent placement in a partially stent-in-stent method was successfully performed with rapid resolution of jaundice (> Fig. 6).

Selective guidewire placement across biliary stricture can be technically challenging, especially in patients after liver transplantation or with hilar biliary stricture [1,2]. To our knowledge, this is the first report demonstrating the utility of SpyDS for guidewire placement across complex hilar malignant biliary stricture at the anastomotic site after liver trans-

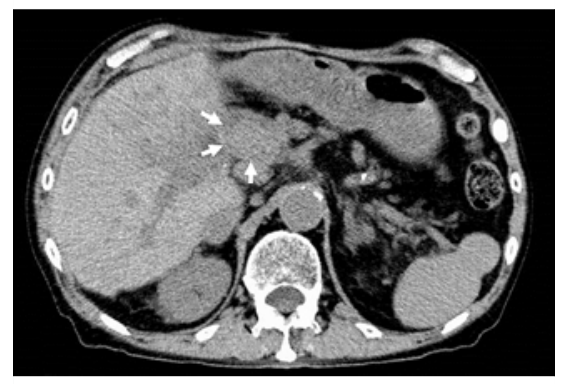

- Fig. 1 Computed tomography showed metastatic hilar lymph nodes (arrow).

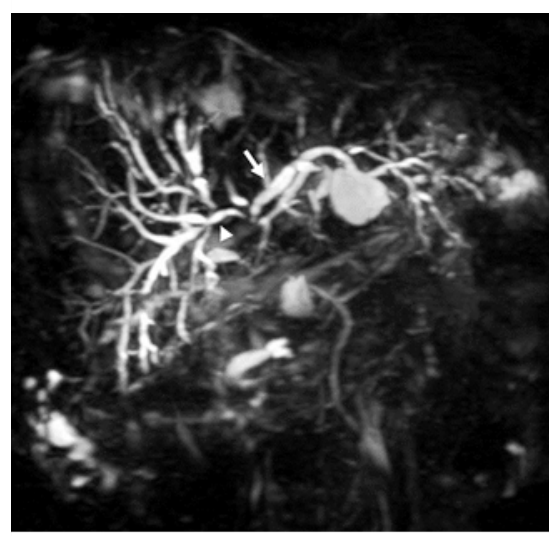

- Fig. 2 Magnetic resonance cholangiopancreatography revealed a high-grade hilar biliary stricture with a dilated left hepatic duct (arrow) and right posterior hepatic duct (arrow head).

plantation. Although several studies reported the effectiveness of cholangioscopy-assisted guidewire placement [35], its success rate was unsatisfactory. The SpyDS has potential advantages over the original Spyglass system: its better image quality, irrigation and 4-way steering. In summary, SpyDS-assisted guidewire passage can be an alternative technique after failed guidewire passage under fluoroscopic guidance.

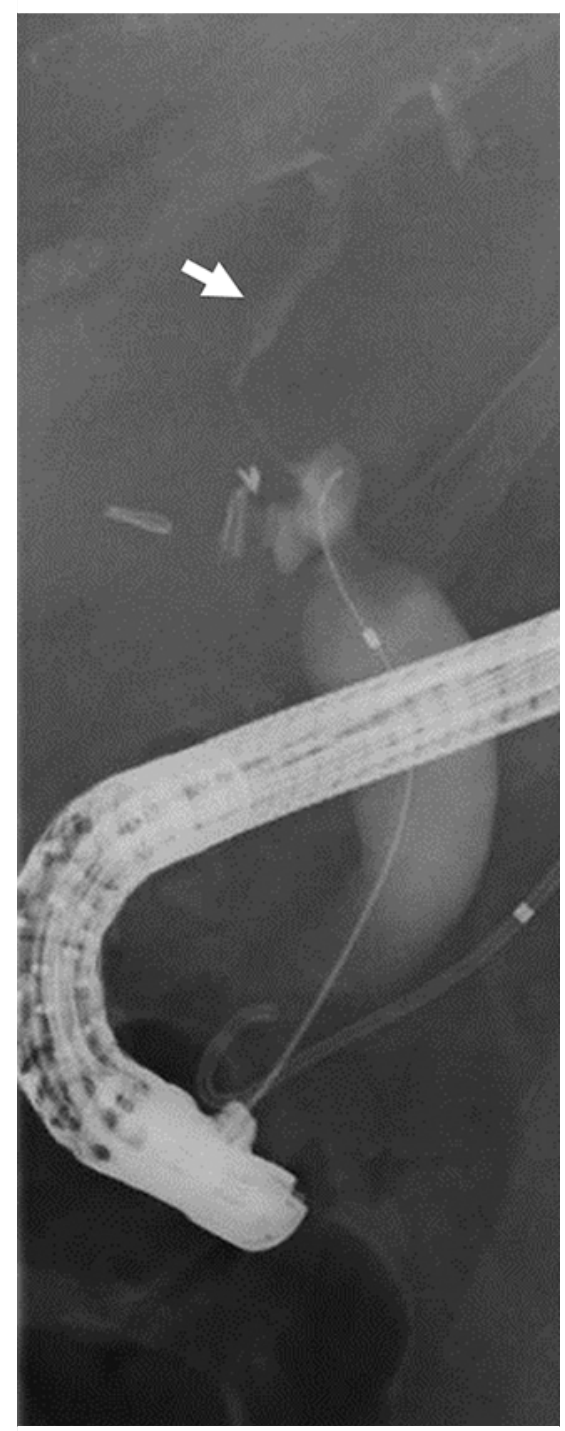

- Fig. 3 Cholangiogram confirmed hilar biliary stricture. The remnant cystic duct and left hepatic duct were visualized after contrast injection (arrow).

Competing interests

None 

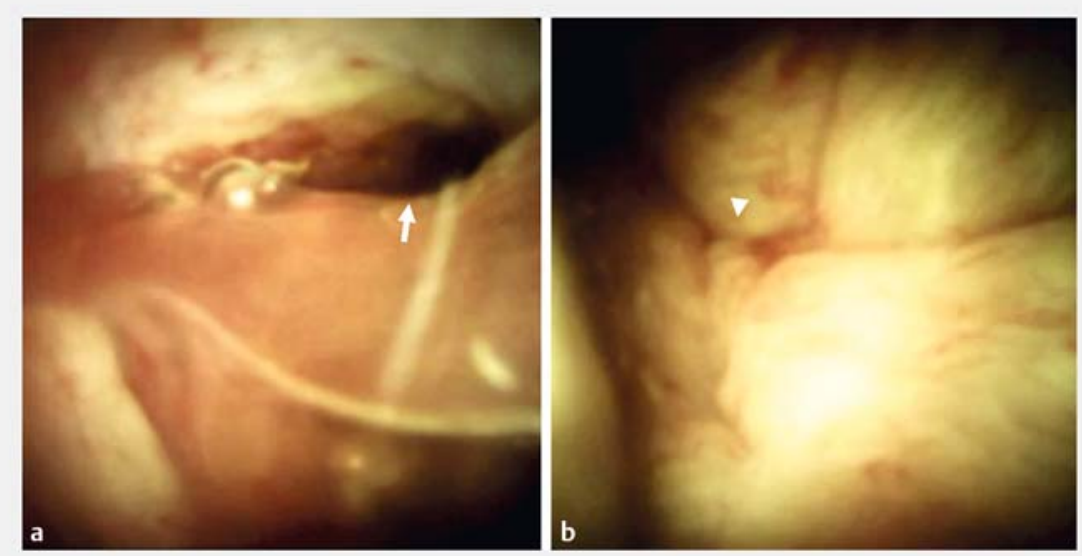

- Fig. 4 The images of SpyGlass DS Direct Visualization System. a The orifice of a remnant cystic duct (arrow). b The distal end of biliary stricture was visualized without a tumor-appearing mucosa (arrow head).
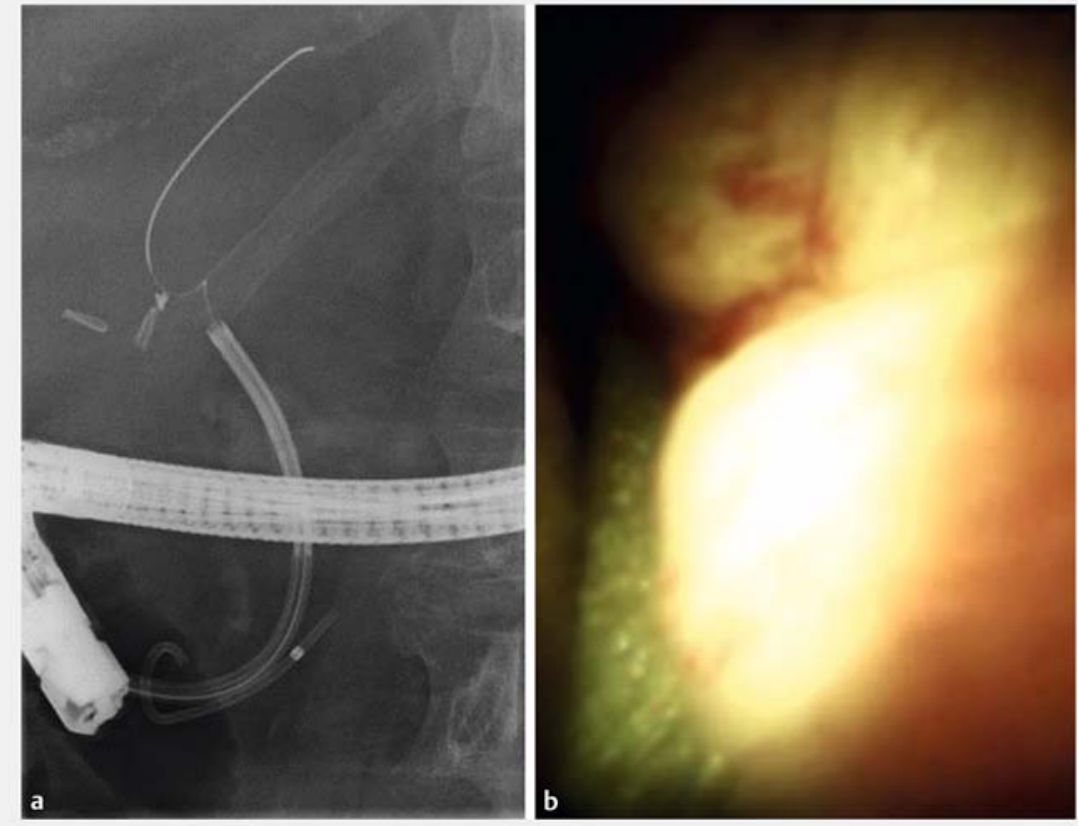

- Fig. 5 Guidewire passage under direct visualization. a Fluoroscopic image of guidewire placement across the stricture. $\mathbf{b}$ Guidewire manipulation under direct visualization of SpyDs.
The authors

Ryunosuke Hakuta, Hirofumi Kogure, Yousuke Nakai, Naminatsu Takahara, Suguru Mizuno, Minoru Tada, Kazuhiko Koike Department of Gastroenterology, Graduate School of Medicine, The University of Tokyo, Tokyo, Japan

\section{Corresponding author}

\section{Yousuke Nakai, MD, PhD}

Department of Gastroenterology, Graduate School of Medicine, The University of Tokyo, 7-3-1 Hongo Bunkyo-ku, Tokyo,

Japan 113-8655

Phone: +81-3-3815-5411

Fax: +81-3-3814-0021

ynakai-tky@umin.ac.jp

\section{References}

[1] Gomez CM, Dumonceau JM, Marcolongo M et al. Endoscopic management of biliary complications after adult living-donor versus deceased-donor liver transplantation. Transplantation 2009; 88: 1280-1285

[2] Kawakubo K, Kawakami H, Toyokawa Y et al. Risk factors for technical failure of endoscopic double self-expandable metallic stent placement by partial stent-in-stent method. J Hepatobiliary Pancreat Sci 2015; 22: 79 85

[3] Woo YS, Lee JK, Noh DH et al. SpyGlass cholangioscopy-assisted guidewire placement for post-LDLT biliary stricutres: a case series. Surg Endosc 2016; 30: 3897-3903

[4] Wright H, Sharma S, Gurakar A et al. Management of biliary stricture guided by the Spyglass Direct Visualization System in a liver transplant recipient: an innovative approach. Gastrointest Endosc 2008; 67: $1201-1203$

[5] Ogura T, Imanishi M, Kurisu Y et al. Prospective evaluation of digital single-operator cholangioscope for diagnostic and therapeutic procedures (with videos). Dig Endosc 2017; 29: $782-789$ 

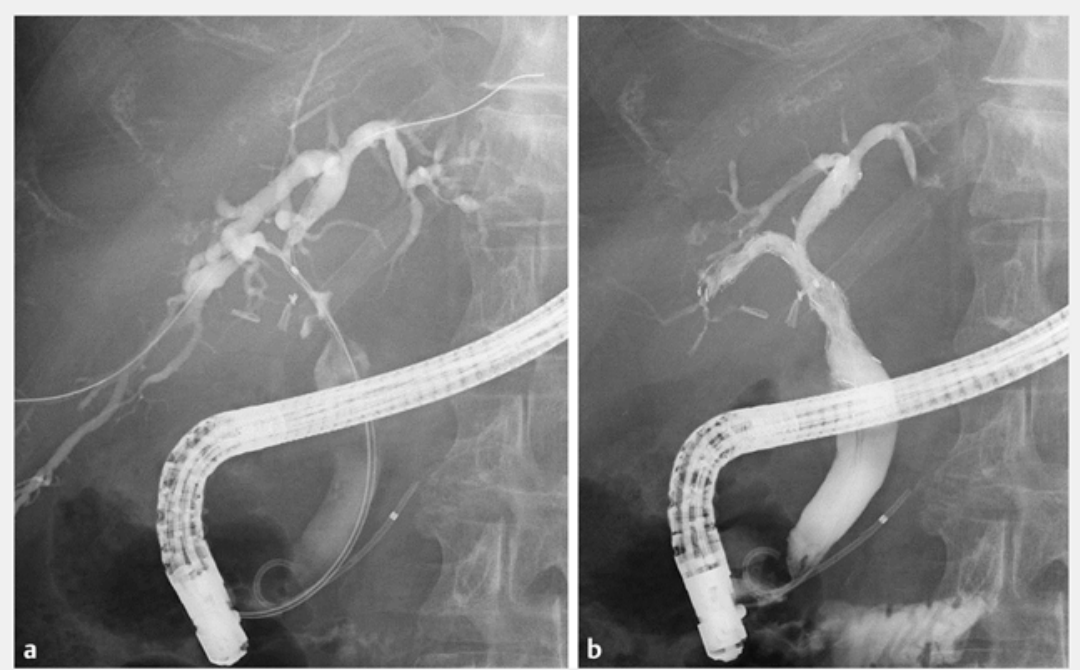

- Fig. 6 Fluoroscopic images of stent placement. a Cholangiogram revealed high-grade hilar biliary stricture. b Bilateral metal stent was performed in a partially stent-in-stent method.
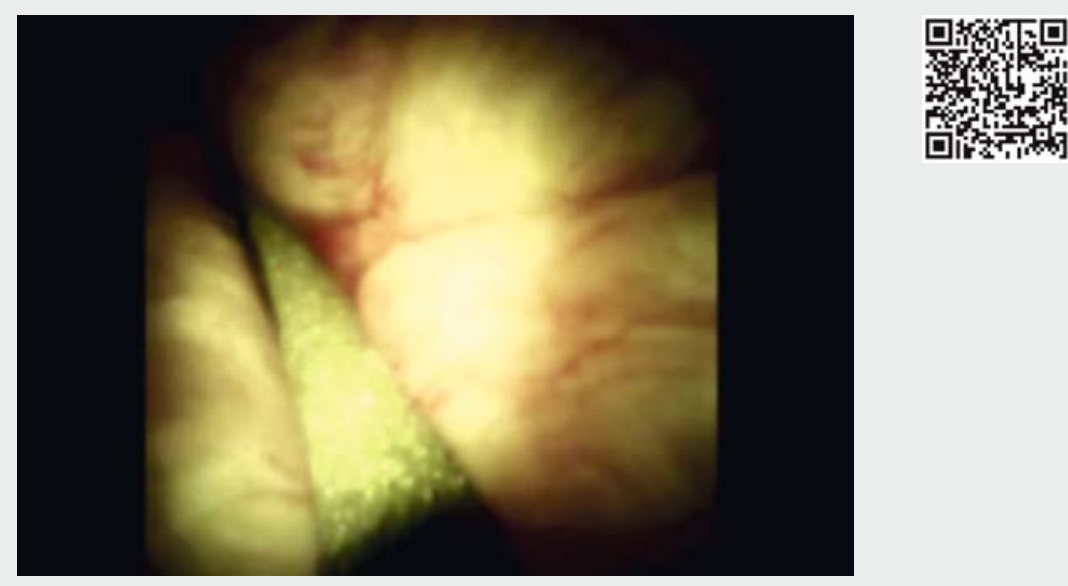

$\square$ Video 1 Successful guidewire placement across hilar malignant biliary stricture under direct visualization using SpyGlass DS Direct Visualization System in a patient after deceased donor liver transplantation.

\section{Bibliography}

DOI https://doi.org/10.1055/s-0043-123817

Published online: 15.12 .2017

Endoscopy 2018; 50: E54-E56

(c) Georg Thieme Verlag KG

Stuttgart $\cdot$ New York

ISSN 0013-726X

\section{ENDOSCOPY E-VIDEOS \\ https://eref.thieme.de/e-videos}

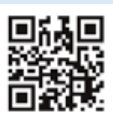

Endoscopy E-Videos is a free access online section, reporting on interesting cases and new

techniques in gastroenterological endoscopy. All papers include a high quality video and all contributions are freely accessible online.

This section has its own submission website at

https://mc.manuscriptcentral.com/e-videos 